Int. J. Electrochem. Sci., 14 (2019) $7608-7622$

\title{
Preparation and Activation of Corn Straw-Based Carbon and Its Application in Supercapacitors
}

Gaofeng Shi ${ }^{*}$ Hongquan Zhang, Yucan Dong*, Qi Zhang, Zhao Wang, Xia Jiang, Yawen Hu, Fenfang Luo, Xin li, Guoying Wang

School of Petrochemical Engineering, Lanzhou University of Technology, NO.287, Langongping Road, Lanzhou, Gansu, China

*E-mail: $\underline{923028088 @ q q . c o m}$

doi: $10.20964 / 2019.08 .38$

Received: 6 April 2019 / Accepted: 25 May 2019 / Published: 30 June 2019

The corn-straw is made into a biomass porous carbon material using three different activation methods. The porous carbon produced using $\mathrm{KOH}$ as the activator shows the best electrochemical performance compared to carbons produced by other methods. When the ratio of $\mathrm{KOH}$ to raw material is $2: 1$ and the activation temperature is $800{ }^{\circ} \mathrm{C}$, the specific surface area of the obtained carbon material is 1067.11 $\mathrm{m}^{2} \cdot \mathrm{g}^{-1}$, and the capacitance reaches $239 \mathrm{~F} \cdot \mathrm{g}^{-1}$ at a current density of $1 \mathrm{~A} \cdot \mathrm{g}^{-1}$. In addition, the capacitance was maintained at $97.12 \%$ after 5000 charge and discharge cycles at a current density of $1 \mathrm{~A} \cdot \mathrm{g}^{-1}$ in a 6 $\mathrm{M} \mathrm{KOH}$ aqueous electrolyte. The conversion of corn-straw into green porous carbon materials not only enables them to be used at high values, but also solves the problem of pollution caused by the treatment of biomass waste.

Keywords: activated carbon; various activation methods; electrode materials; capacitive performance

\section{$\underline{\text { FULL TEXT }}$}

(C) 2019 The Authors. Published by ESG (www.electrochemsci.org). This article is an open access article distributed under the terms and conditions of the Creative Commons Attribution license (http://creativecommons.org/licenses/by/4.0/). 